\title{
Performance determinants, running energetics and spatiotemporal gait parameters during a treadmill ultramarathon
}

\author{
Christopher C. F. Howe ${ }^{1} \mathbb{D}$. Nicola Swann ${ }^{1}$ - Owen Spendiff ${ }^{1} \cdot$ Anna Kosciuk $^{1}$ - Elizabeth K. L. Pummell ${ }^{1}$. \\ Hannah J. Moir ${ }^{1}$
}

Received: 11 December 2020 / Accepted: 13 February 2021 / Published online: 11 March 2021

(c) The Author(s) 2021

\begin{abstract}
Purpose The objective of this study was to investigate the changes in metabolic variables, running energetics and spatiotemporal gait parameters during an $80.5 \mathrm{~km}$ treadmill ultramarathon and establish which key predictive variables best determine ultramarathon performance.

Methods Twelve participants ( 9 male and 3 female, age $34 \pm 7$ years, and maximal oxygen uptake $\left(\dot{V} \mathrm{O}_{2 \max }\right)$ $60.4 \pm 5.8 \mathrm{ml} \cdot \mathrm{kg}^{-1} \cdot \mathrm{min}^{-1}$ ) completed an $80.5 \mathrm{~km}$ time trial on a motorised treadmill in the fastest possible time. Metabolic variables: oxygen consumption $\left(\dot{V} \mathrm{O}_{2}\right)$, carbon dioxide production $\left(\dot{V} \mathrm{CO}_{2}\right)$ and pulmonary ventilation $\left(\dot{V}_{\mathrm{E}}\right)$ were measured via indirect calorimetry every $16.1 \mathrm{~km}$ at a controlled speed of $8 \mathrm{~km} \cdot \mathrm{h}^{-1}$ and used to calculate respiratory exchange ratio (RER), the energy cost of running $(\mathrm{Cr})$ and fractional utilisation of $\dot{V} \mathrm{O}_{2 \max }(F)$. Spatiotemporal gait parameters: stride length (SL) and cadence (SPM) were calculated via tri-axial accelerometery.

Results Trial completion time was 09:00:18 \pm 01:14:07 (hh:mm:ss). There were significant increases in $\dot{V} \mathrm{O}_{2}, \mathrm{Cr}, F, \dot{V}_{\mathrm{E}}$ and heart rate (HR) $(p<0.01)$; a significant decrease in RER $(p<0.01)$ and no change in SL and SPM $(p>0.05)$ across the measured timepoints. $F$ and $\mathrm{Cr}$ accounted for $61 \%$ of the variance in elapsed finish time $\left(R_{\mathrm{adj}}^{2}=0.607, p<0.01\right)$.

Conclusion A treadmill ultramarathon elicits significant changes in metabolic variables, running energetics and spatiotemporal gait parameters. With $F$ and $\mathrm{Cr}$ explaining $61 \%$ of variance in finish time. Therefore, those able to maintain a higher $F$, while adopting strategies to minimise an increase in $\mathrm{Cr}$ may be best placed to maximise ultramarathon performance.
\end{abstract}

Keywords Endurance $\cdot$ Running $\cdot$ Oxygen cost $\cdot$ Stride frequency $\cdot$ Stride length $\cdot$ Ultra-marathon

$\begin{array}{ll}\text { Abbreviations } \\ \text { ANOVA } & \text { Analysis of variance } \\ \text { BMI } & \text { Body mass index } \\ \mathrm{CHO} & \text { Carbohydrate } \\ \mathrm{Cr} & \text { Energy cost of running } \\ F & \text { Fractional utilisation of } \dot{V} \mathrm{O}_{2 \max } \\ \mathrm{HR} & \text { Heart rate } \\ \mathrm{HR}_{\max } & \text { Maximum recorded heart rate } \\ \text { RER } & \text { Respiratory exchange ratio } \\ \text { RPE } & \text { Rating of perceived exertion }\end{array}$

Communicated by Jean-René Lacour.

Christopher C. F. Howe

c.howe@kingston.ac.uk

1 School of Life Sciences, Pharmacy and Chemistry, Faculty of Science Engineering and Computing, Kingston University London, Penryhn Road, Kingston upon Thames KT1 2EE, UK
RMR Resting metabolic rate

SL Stride length

SPM Strides per minute

$\dot{V} \mathrm{CO}_{2} \quad$ Carbon dioxide production

$\dot{V}_{\mathrm{E}} \quad$ Pulmonary ventilation

$\dot{V} \mathrm{O}_{2} \quad$ Oxygen uptake

$\dot{V} \mathrm{O}_{2 \max } \quad$ Maximal oxygen uptake capacity

$\mathrm{V}_{\dot{V} \mathrm{O}_{2 \max }} \quad$ Maximum treadmill speed obtained at $\dot{V} \mathrm{O}_{2 \max }$

\section{Introduction}

Characteristically, ultramarathons are defined as any distance beyond the $42.2 \mathrm{~km}$ of the traditional marathon (Hoffman et al. 2010; Knechtle 2012; Krouse et al. 2011; Rüst et al. 2014). Global participation in ultramarathons has increased rapidly over the past 25 years with most individuals taking part in event distances ranging from 50 to 161 km (DUV Ultra Marathon Statistics (2019) Available 
from: http://statistik.d-u-v.org.). This increase in ultramarathon participation has generated a healthy growth in research around the topic, investigating the complex interaction of several research areas, from physiological, biomechanical, psychological (Howe et al. 2019), and nutritional (Knechtle and Nikolaidis 2018). It has been well documented that a high-level performance in endurance running events up to the marathon, is dependent on a combination of physiological characteristics, such as a high maximal oxygen consumption $\left(\dot{V} \mathrm{O}_{2 \max }\right)$, a large fractional utilisation of $\dot{V}$ $\mathrm{O}_{2 \max }(F)$, a low energetic cost of running $(\mathrm{Cr})$, as well as optimised muscle activation, recruitment and running biomechanics (Gimenez et al. 2013; Joyner and Coyle 2008; Lazzer et al. 2012; Millet et al. 2011; Saunders et al. 2004; Sjödin and Svedenhag 1985). Cost of running (Cr) is a measure of running economy/efficiency and defined as the energy demand for a given submaximal running speed (Saunders et al. 2004). Running economy is often reported as a stronger predictor of endurance running performance than $\dot{V} \mathrm{O}_{2 \max }$ alone (Conley and Krahenbuhl 1980; Daniels 1985), with the most common measure being the oxygen required to cover a given distance (Foster and Lucia 2007; Ingham et al. 2008). However, it has been proposed that $\mathrm{Cr}$ is a more accurate predictor of performance than oxygen cost $\left(\dot{V} \mathrm{O}_{2}\right)$ (Beck et al. 2018; Fletcher et al. 2009), as $\dot{V}$ $\mathrm{O}_{2}$ does not account for substrate oxidation rates, with the energy yield per volume of oxygen consumed $\sim 7 \%$ greater for carbohydrate (CHO) over lipid oxidation (Péronnet and Massicotte 1991). This is a key factor when measuring the energy required during ultramarathons due to the clear shift in substrate oxidation from CHO to lipids (Davies and Thompson 1986; Gimenez et al. 2013; Howe et al. 2018). Traditionally, an increase in $\mathrm{Cr}$ is observed in distances up to the marathon (Brueckner et al. 1991); however, the literature regarding changes in $\mathrm{Cr}$ during ultramarathons is still open for debate (Vernillo et al. 2017). Previously, it has been demonstrated in a $90 \mathrm{~km}$ multi-stage ultramarathon, whereby that $\dot{V} \mathrm{O}_{2 \max }, F$ and $\mathrm{Cr}$ explained $87 \%$ of the variance in performance time (Lazzer et al. 2012). Whilst some studies have demonstrated an increase in $\mathrm{Cr}$ (Gimenez et al. 2013; Vernillo et al. 2015), others show no change (Balducci et al. 2017; Fusi et al. 2008; Schena et al. 2014; Vernillo et al. 2015), and even a decrease in Cr post-ultramarathon (Vernillo et al. 2014,2016). However, notable differences between studies especially in varying distances and typographies of the ultramarathons studied make it difficult to allow direct comparison. Nevertheless, theories that have been postulated to explain the variation in reported $\mathrm{Cr}$ in ultramarathons include, a decline in the functional capacity of the respiratory system (Wuthrich et al. 2015), with some studies showing an increase of $\sim 18 \%$ in pulmonary ventilation $\left(\dot{V}_{\mathrm{E}}\right)$ (Millet et al. 2000; Vernillo et al. 2014), however, other studies have shown a decrease of between $3-10 \%$ in
$\dot{V}_{\text {E }}$ post-ultramarathon (Gimenez et al. 2013; Lazzer et al. 2015; Schena et al. 2014), in distances ranging between 60 and $330 \mathrm{~km}$. Alterations in neuromuscular function are also evident, due to the fatiguing nature and muscle damage accrued during ultramarathons (Knechtle and Nikolaidis 2018; Nieman et al. 2005), which requires increased neural input to the working muscles to maintain the same force output, resulting in an increase in oxygen demand and therefore increase in $\mathrm{Cr}$ (Bigland-Ritchie and Woods 1974). This may lead to changes in muscle activation, through the recruitment of less efficient type II muscle fibres causing changes in biomechanical parameters (Degache et al. 2016; Morin et al. 2011b), specifically changes in spatiotemporal gait parameters, such as increased stride frequency [steps per minute (spm)] and reduced stride length (SL) (Cavanagh and Kram 1989; Cavanagh and Williams 1982; Moore 2016). While it is possible to extrapolate some data generated from short endurance running research (Millet et al. 2011), due to the extreme and demanding nature of ultramarathon running this is not always possible (Burns et al. 2019; Gimenez et al. 2013; Millet et al. 2002; Scheer et al. 2018) due to event specific inter- and intra-variability and range of training status and expertise level of participants. The differing methodological approaches employed in ultramarathon research make direct comparisons of data challenging, both between events and within an individual event (Vernillo et al. 2017).

Ultramarathons can be single- or multi-stage, have varying terrain across and within events (treadmill, track, desert and mountainous etc.) along with environmental factors (temperature and altitude), all of which elicit different metabolic responses (Burns et al. 2019; Gimenez et al. 2013; Lazzer et al. 2014; Millet et al. 2002; Scheer et al. 2018). However, due to the remote nature of many ultramarathons and the logistical challenges of collecting data, the majority of studies have only been able to collect pre- and post-ultramarathon measurements (Fusi et al. 2008; Lazzer et al. 2012; Vernillo et al. 2014), with few investigating the adjustments and change in energetic and metabolic variables during an ultramarathon (Gimenez et al. 2013; Millet et al. 2011). The use of treadmill running, whilst different to ecologically valid ultramarathon races/events, due to the lack of competition and effect of environmental factors, provides a useful tool to collect and facilitate real-time 'in-event' data collection (Morin and Sève 2011).

Therefore, the aim of this study was to investigate the changes and adjustments in running energetics and metabolic variables and spatiotemporal gait parameters during an $80.5 \mathrm{~km}$ treadmill ultramarathon and establish which key predictive variables best determine ultramarathon performance. It was first hypothesised that completing a treadmill ultramarathon would elicit an increase in $\mathrm{Cr}$ and 
SPM with a decrease in SL. Second, it was hypothesised that a combination of a high $\dot{V} \mathrm{O}_{2 \max }$, large $F$ and low $\mathrm{Cr}$ would all contribute to overall performance.

\section{Methodology}

\section{Experimental design and participants}

Fourteen endurance runners with a minimum of 3 years running experience and no known injuries were initially recruited via social media and 'word of mouth' through the local ultramarathon community, but due to the nature of the study protocol, only twelve participants ( 9 male and 3 female) completed the $80.5 \mathrm{~km}$ distance. The study was approved by the Faculty of Science, Engineering and Computing Ethics Committee at Kingston University London and all volunteer participants provided written informed consent to participate. All procedures were conducted in accordance with the Declaration of Helsinki. Participant anthropometric and physiological characteristics are reported in Table 1. All participants were required to visit the human performance laboratory at Kingston University London on two occasions (Visit 1: baseline measurements and maximal discontinuous incremental $\dot{V} \mathrm{O}_{2 \max }$ test. Visit 2: $80.5 \mathrm{~km}$ treadmill ultramarathon), with visits separated by at least one week but no longer than three weeks apart.

\section{Instruments}

Metabolic variables $\left(\dot{V} \mathrm{O}_{2}, \dot{V} \mathrm{CO}_{2}\right.$ and $\left.\dot{V}_{\mathrm{E}}\right)$ were measured via indirect calorimetry using the Oxycon Pro metabolic cart (Vyaire, UK), which was calibrated according to manufacturer guidelines prior to every measurement. Spatiotemporal parameters were calculated from raw tri-axial accelerometer data (GT3X +, ActiGraph, LLC, Fort Walton Beach, FL)

Table 1 Participant characteristics and maximal discontinuous incremental $\dot{V} \mathrm{O}_{2 \max }$ test $(n=12)$

\begin{tabular}{lc}
\hline Variable & Mean \pm SD \\
\hline Age (years) & $34 \pm 7$ \\
Stature $(\mathrm{cm})$ & $173.7 \pm 7.3$ \\
Body mass $(\mathrm{kg})$ & $68.4 \pm 7.4$ \\
BMI $\left(\mathrm{kg} / \mathrm{m}^{2)}\right.$ & $22.6 \pm 1.9$ \\
Body fat $(\%)$ & $15.1 \pm 5.1$ \\
Ave weekly training distance $(\mathrm{km})$ & $74 \pm 27$ \\
$\dot{V} \mathrm{O}_{2 \max }\left(\mathrm{ml} \cdot \mathrm{min}^{-1}\right)$ & $4168 \pm 482$ \\
$\dot{V} \mathrm{O}_{2 \max }\left(\mathrm{ml} \cdot \mathrm{kg}^{-1} \cdot \mathrm{min}^{-1}\right)$ & $60.4 \pm 5.8$ \\
$\mathrm{HR}_{\max }(\mathrm{bpm})$ & $187 \pm 13$ \\
$\mathrm{~V}_{\dot{V} \mathrm{O}_{2 \max }}\left(\mathrm{km} \cdot \mathrm{h}^{-1}\right)$ & $17.3 \pm 1.8$ \\
\hline
\end{tabular}

$B M I$ body mass index, $\dot{V} O_{2 \max }$ maximal oxygen uptake capacity, $H R_{\max }$ maximum recorded heart rate, $V_{\dot{V O}{ }_{2 \max }}$ maximum treadmill speed obtained which was initialised using the device software (Actilife 5, ActiGraph, LLC, Fort Walton Beach, FL) and set to collect data at a sampling rate of $100 \mathrm{~Hz}$. Raw accelerometer data were analysed for peak vertical accelerations at the hip via a custom MATLAB (The MathWorks, Inc., Natick, MA, USA) script to calculate spatiotemporal gait parameters; stride time, cadence (strides per minute (SPM)) and stride length (SL). Tri-axial accelerometers have previously demonstrated suitable levels of agreement in identifying spatiotemporal gait parameters when compared to an infrared camera laboratory-based system (Lee et al. 2010). The GT3X + was placed inside a neoprene pouch attached to an elasticised waistband which was then attached on the participant's dominant hip on the mid-axillary line for the duration of the $80.5 \mathrm{~km}$ trial. HR was measured continuously throughout all trials using a HR strap fitted around the participant's chest and the data transmitted via telemetry (Polar Electro Oy, Kempele Finland).

\section{Baseline measurements and maximal discontinuous incremental $\mathrm{VO}_{2 \max }$ test}

Participant's anthropometrics and body composition were measured at baseline. Stature $(\mathrm{cm})$ was measured using a floor stadiometer (Holtain Ltd., Dyfed, Wales) and body mass (kg) using electronic scales (Seca, Vogel and Halke, Germany). Body fat $\%$ was estimated using air-displacement plethysmography (Bod Pod Cosmed, Rome, Italy). Participant's maximal oxygen uptake $\left(\dot{V} \mathrm{O}_{2 \max }\right)$, performed on a motorised treadmill (H/P/Cosmos, Nussdorf-Traunstein, Germany), was assessed using a maximal discontinuous incremental protocol to volitional exhaustion. The treadmill (H/P/Cosmos Venus) was set at an incline of $1 \%$ (Jones and Doust 1996) and an initial speed of $10 \mathrm{~km} \cdot \mathrm{h}^{-1}$ for a period of $6 \mathrm{~min}$, followed by a $1 \mathrm{~min}$ standing rest for the collection of a capillary blood sample (Biosen C-Line Sport EKF diagnostic, Germany). The treadmill speed was then increased by $1.5 \mathrm{~km} \cdot \mathrm{h}^{-1}$ every $3 \mathrm{~min}$ followed by a $1 \mathrm{~min}$ standing rest to allow for capillary blood collection to measure blood lactate $\left(\mathrm{mmol} \cdot \mathrm{L}^{-1}\right)$, this was repeated until volitional exhaustion. The discontinuous protocol was designed to allow comparison to previous studies (Gimenez et al. 2013) as well as to allow participants to run at the higher speeds for a sufficient period of time to provide steady-state values.

\section{$80.5 \mathrm{~km}$ treadmill ultramarathon}

Visit two comprised an $80.5 \mathrm{~km}$ treadmill ultramarathon. To replicate a race of this distance, participants were instructed to complete the distance in the fastest possible time, with the exception of a 3 min period at a control speed of $8 \mathrm{~km} \cdot \mathrm{h}^{-1}$, beginning $10 \mathrm{~min}$ after commencing the trial $(0 \mathrm{~km})$ and then at every $16.1 \mathrm{~km}$ interval thereafter. Throughout each 
3 min period, respiratory variables were measured via indirect calorimetry (Oxycon Pro, Vyaire, UK). The last minute of each 3 min period was used for analysis once steady state was achieved. Steady state was checked using the method outlined by De Ruiter et al. (2014), by calculating the slope of a linear regression line fitted through the $\dot{V} \mathrm{O}_{2}$ data of the third min, where steady state was confirmed if zero slope fell within the individual $95 \%$ confidence intervals. The use of a control speed enabled both inter- and intra-direct comparison by removing self-selected velocity as a confounding factor. The $8 \mathrm{~km} \cdot \mathrm{h}^{-1}$ speed was selected to allow comparison to previous research as well as this speed having been suggested to best represent an average pace for this type of activity (Gimenez et al. 2013; Millet et al. 2011). The accelerometer and HR data were time-matched with the respiratory variables for subsequent analysis. Food and drink were available ad libitum during the entire duration of the trial and self-selected according to the participant's preference, to replicate their habitual ultramarathon practices. All nutritional intake was recorded and analysed through nutritional analysis software (Dietplan 6 Software, Horsham, U.K.). Further details are reported in previously published work (Howe et al. 2019).

\section{Energy cost of running}

The last minute of the 3 min collection period when steady state was observed was averaged and used to calculate $\mathrm{Cr}$. $\mathrm{Cr}$ is expressed as joules per kilogram per meter $\left(\mathrm{J} \cdot \mathrm{kg}^{-1} \cdot \mathrm{m}^{-1}\right)$, using the associated caloric equivalent of oxygen $\left(\mathrm{kJ} \cdot \mathrm{L}^{-1}\right)$ depending on respiratory exchange ratio (RER) (Péronnet and Massicotte 1991) using the following equation.

$\mathrm{Cr}\left(\mathrm{J} \cdot \mathrm{kg}^{-1} \cdot \mathrm{m}^{-1}\right)=\dot{V} \mathrm{O}_{2}\left(\mathrm{~L} \cdot \mathrm{min}^{-1}\right)$. caloric equivalent of $\mathrm{O}_{2}\left(\mathrm{~kJ} \cdot \mathrm{L}^{-1}\right) /$ body mass $(\mathrm{kg}) /$ speed $\left(\mathrm{m} \cdot \mathrm{min}^{-1}\right)$.

Due to the issues around baseline subtraction of resting metabolic rate (RMR), it cannot be confirmed that RMR is maintained at the same rate during running compared to rest (Fletcher et al. 2009; Stainsby and Barclay 1970), the decision was made not to subtract RMR. All respiratory variables that are expressed relative to body mass are adjusted to the actual body mass loss as measured at every $16.1 \mathrm{~km}$ split throughout the $80.5 \mathrm{~km}$ trial.

\section{Statistical analysis}

All data were assessed for normality via the Shapiro-Wilk normality test. Differences between $16.1 \mathrm{~km}$ intervals for all variables measured were analysed by one-way repeated measures analysis of variance (ANOVA) with Bonferroni post hoc. Effect sizes were calculated using partial ETA ${ }^{2}$ $\left(\eta p^{2}\right)$ where $0.01=$ small; $0.06=$ medium; and $0.14=$ large effect (Field 2018). Pearson's correlations $(r)$ were used to examine for significant relationships between potential determinants of ultramarathon performance and elapsed finished time for the $80.5 \mathrm{~km}$ trial. Those determinants found to have a significant linear relationship with performance time $(p \leq 0.05)$, were entered into a multiple linear regression to assess the relative contribution to performance. Delta change $(\Delta)$ of selected variables was calculated from the $80.5 \mathrm{~km}$ distance measurement minus the start $0 \mathrm{~km}$ distance measurement and expressed as a percentage of start $0 \mathrm{~km}$ distance measurement $(\% \Delta)$. All data were analysed using IBM SPSS Statistics 24 (SPSS Inc., Chicago, IL, USA) and presented as mean \pm SD and the alpha level was set at $p \leq 0.05$.

\section{Results}

\section{Performance measures}

The average elapsed time and average moving time to complete the $80.5 \mathrm{~km}$ trial were $540 \pm 74$ and $500 \pm 64 \mathrm{~min}$, respectively $\left(9.81 \pm 1.31\right.$ and $9.1 \pm 1.28 \mathrm{~km} \cdot \mathrm{h}^{-1}$, respectively). The mean speed over the $80.5 \mathrm{~km}$ TT expressed as a percentage of speed associated with $\dot{V} \mathrm{O}_{2 \max }$ equals $57.0 \pm 6.0 \% \mathrm{~V}_{\dot{V O}_{2 \max }}$ when considering moving time on the treadmill. When expressed as elapsed time, including comfort breaks etc., akin to a race and time taken to perform measurements, the mean $F$ equals $66.5 \pm 3.0 \% \dot{V} \mathrm{O}_{2 \max }$ and mean elapsed $\% \mathrm{~V}_{\dot{V} \mathrm{O}_{2 \max }}$ equals $52.8 \pm 6.7 \%$.

\section{Body mass and nutritional intake}

There was an overall significant decrease in participant body mass over the $80.5 \mathrm{~km}$ TT $(F(1.28,14.08)=68.97$, $\left.p<0.01, \eta p^{2}=0.862\right)$ with a significant decrease identified at all $16.1 \mathrm{~km}$ splits $(p<0.05)$, apart from between 48.3 and $64.4 \mathrm{~km}(p=0.097)$. Pre- to post-trial exerciseinduced body mass loss was $2.6 \pm 0.97 \mathrm{~kg}(p<0.001)$, which equated to a percentage loss of $3.9 \pm 1.32 \%$. Total mean energy intake during the $80.5 \mathrm{~km}$ trial was $6.68 \pm 2.35$ mega joules and $1588 \pm 553$ kilocalories. Macronutrient intake was $37.18 \pm 12.6 .0 \mathrm{~g} \cdot \mathrm{h}^{-1} \mathrm{CHO}, 2.64 \pm 2.0 \mathrm{~g} \cdot \mathrm{h}^{-1} \mathrm{fat}$ and $8.33 \pm 1.1 \mathrm{~g} \cdot \mathrm{h}^{-1}$ protein. Further details can be seen in previously published work (Howe et al. 2019).

\section{$\mathrm{O}_{2}$ cost, $\mathrm{Cr}$ and $\mathrm{F}$}

A significant increase in relative $\dot{V} \mathrm{O}_{2}\left(\mathrm{ml} \cdot \mathrm{kg}^{-1} \cdot \mathrm{min}^{-1}\right)$ adjusted for the reduction in body mass throughout the $80.5 \mathrm{~km}$ TT at the control speed was observed ( $F(5$, $\left.55)=21.33, p<0.01, \eta p^{2}=0.66\right)$. Post hoc analysis identified a significant increase from the start of the TT to distance points of 48.3, 64.4 and $80.5 \mathrm{~km}(p<0.05)$ and this continued to increase up to the completion of the $80.5 \mathrm{~km}$ ultramarathon $(p<0.01)$ (Fig. 1a). A significant increase was in the 



Fig. 1 Change in a $\dot{V} \mathrm{O}_{2}\left(\mathrm{ml} \cdot \mathrm{kg}^{-1} \cdot \mathrm{min}^{-1}\right)$, b energy cost of running $\left(\mathrm{Cr}, \mathrm{J} \cdot \mathrm{kg}^{-1} \cdot \mathrm{m}^{-1}\right)$, c fractional utilisation of $\dot{V} \mathrm{O}_{2 \max }\left(F, \% \dot{V} \mathrm{O}_{2 \max }\right)$, d minute ventilation $\left(\dot{V}_{\mathrm{E}}\right)$ e respiratory exchange ratio (RER), $\mathbf{f} \mathrm{O}_{2}$ cost of running $\left(\mathrm{mlO}_{2} \cdot \mathrm{kg}^{-1} \cdot \mathrm{km}^{-1}\right)$ and $\mathbf{g}$ heart rate $\left(\mathrm{bpm}^{-1}\right)$ measured at

$16.1 \mathrm{~km}$ intervals at the control speed. Solid black line: mean \pm SD. Significance set at $* p<0.05, * * p<0.01, * * * p<0.001$. Grey lines individual participant responses 
$\mathrm{O}_{2}$ cost of running at the control speed when expressed as $\mathrm{mlO}_{2} \cdot \mathrm{kg}^{-1} \cdot \mathrm{km}^{-1}\left(F(5,55)=21.18, p<0.001, \eta \mathrm{p}^{2}=0.658\right)$. Post hoc analysis identified a significant increase in the $\mathrm{O}_{2}$ cost between the start and 48.3, 64.4 and $80.5 \mathrm{~km}(p<0.05$, $p<0.01$ and $p<0.001$, respectively) (Fig. 1f). There was a significant increase in $\mathrm{Cr}$ when RER was taken into account $\left(F(5,55)=15.65, p<0.001, \eta p^{2}=0.59\right)$. Post hoc analysis identified a significant increase from the start to the 64.4 and $80.5 \mathrm{~km}$ distances ( $p<0.05$ and $p<0.01$, respectively), and from the $16.1 \mathrm{~km}$ distance to 32.2 and $80.5 \mathrm{~km}(p<0.05$ and $p<0.01$, respectively), between 32.2 and $80.5 \mathrm{~km}(p<0.01)$ and between 48.3 and $80.5 \mathrm{~km}(p<0.01)$ (Fig. 1b). A significant increase $F$ was observed $(F(5,55)=10.95, p<0.01$, $\left.\eta \mathrm{p}^{2}=0.5\right)$ at the control speed, with post hoc analysis showing a significant increase from the start to finish and the 16.1, 32.2 and $48.3 \mathrm{~km}$ distance points to the finish $(p<0.05)$ (Fig. 1c).

\section{$R E R, \dot{V}_{E}$, and $H R$}

A significant decrease in RER was observed at the control speed $\left(F(1.96,2.54)=17.21, p<0.01, \eta p^{2}=0.61\right)$, with post hoc analysis identifying a significant decrease from the start $(0 \mathrm{~km})$ and all $16.1 \mathrm{~km}$ intervals, as well as between 16.1 and 32.2 and $48.3 \mathrm{~km}$ splits $(p<0.05)$, after which RER plateaus (Fig. 1e). There was a significant overall increase in $\dot{V}_{\mathrm{E}}$ at the control speed of $8 \mathrm{~km} \cdot \mathrm{h}^{-1}(F(5,55)=3.64, p<0.01$, $\left.\eta \mathrm{p}^{2}=0.5\right)$, with post hoc analysis showing a significant increase from the start to 64.4 and $80.5 \mathrm{~km}(p<0.05$ and $p<0.01$, respectively). There was also a significant increase between 32.2 and $64.4 \mathrm{~km}(p<0.05)$ and between 48.3 and $64.4 \mathrm{~km}(p<0.01)$ (Fig. 1d). At the control speed, there was an observed mean $\mathrm{HR}$ of $75 \pm 4 \%$ of $\mathrm{HR}_{\max }$. HR significantly increased over the duration of the $80.5 \mathrm{~km}$ trial at the control speed $\left(F(2.5,27.9)=10.31, p<0.01, \eta p^{2}=0.48\right)$. Post hoc analysis identified a significant increase from the start $(0 \mathrm{~km})$ to $32.2,48.3,64.4$ and $80.5 \mathrm{~km}$ distances $(p<0.05)$ after which a plateau is evident (Fig. 1g).

\section{Spatiotemporal gait parameters}

There was no significant change in the spatiotemporal parameters measured across all $16.1 \mathrm{~km}$ measurement splits at the control speed of $8 \mathrm{~km} \cdot \mathrm{h}^{-1}$; SPM ( $F(2.02$, $22.3)=1.76, p=0.195, \eta p^{2}=0.14$, observed power $\left.=0.33\right)$, and $\operatorname{SL}\left(F(2.4,26.3)=2.28, p=0.11, \eta p^{2}=0.17\right.$, observed power $=0.46)$ at the control speed $($ Fig. $2 \mathrm{a}, \mathrm{b})$.

\section{Pearson's correlations and multiple linear regression}

Pearson's correlations were performed between elapsed finish time and endurance performance determinants $\left(\dot{V} \mathrm{O}_{2 \max }\right.$,
$F$, and $\mathrm{Cr}$ ); where $F$ and $\mathrm{Cr}$ were measured for 3 min periods at $16.1 \mathrm{~km}$ intervals at a self-selected speed and averaged to give a mean $F$ and $\mathrm{Cr}$ over the $80.5 \mathrm{~km}$ ultramarathon. There were significant linear relationships between both $F$ and $\mathrm{Cr}$ and elapsed finish time $(r=0.63, p=0.015$ and $r=0.61$, $p=0.018$, respectively); however, there was no relationship between $\dot{V} \mathrm{O}_{2 \max }$ of participants and their performance time $(r=-0.23, p=0.24)$. Due to absence of a relationship between $\dot{V} \mathrm{O}_{2 \max }$ and finish time only, $F$ and $\mathrm{Cr}$ were entered into the multiple linear regressions, which identified a significant relationship between these determinants and finish time $\left(F(2,9)=9.5, p=0.06, R^{2}=0.68, R_{\text {adj }}^{2}=0.61\right)$. Therefore, in the study cohort, $61 \%$ of the variance in elapsed finish time can be explained by a higher sustained $F$ and lower $\mathrm{Cr}$ throughout the $80.5 \mathrm{~km}$ ultramarathon. There were no significant correlations between mean $F$ and $\mathrm{V}_{\dot{V} \mathrm{O}_{2 \max }}(\%)$ sustained throughout the $80.5 \mathrm{~km}$ trial compared to $\Delta \mathrm{Cr}(\%)$ using the control speed $(r=0.14 ; p=0.68$ and $r=0.41$; $p=0.19$, respectively; Fig. 3 ). As well as no significant correlation between $\Delta \mathrm{SL}(\%)$ and $\Delta$ cadence $(\%)$ at self-selected running speed when compared to $\Delta \mathrm{Cr}(\%)(r=-0.23$; $p=0.48$ and $r=0.02 ; p=0.95$, respectively; Fig. 4). There was a significant positive correlation between $\mathrm{Cr}$ and the oxygen cost of running $\left(\mathrm{mlO}_{2} \cdot \mathrm{kg}^{-1} \cdot \mathrm{km}^{-1}\right),(r=0.99$, $p<0.001)$.

\section{Discussion}

This study aimed to determine the variation in metabolic variables, running energetics and spatiotemporal gait parameters during an $80.5 \mathrm{~km}$ treadmill ultramarathon and identify the level to which key variables $\left(\dot{V} \mathrm{O}_{2 \max }, F\right.$ and $\mathrm{Cr}$ ) influence overall performance. The use of a control speed of $8 \mathrm{~km} \cdot \mathrm{h}^{-1}$ with $16.1 \mathrm{~km}$ interval analysis allowed for precise intra- and inter-observation of changes in the measured parameters throughout the duration of an ultramarathon treadmill run. The key findings illustrated a significant increase in $\dot{V} \mathrm{O}_{2}, \mathrm{Cr}, F, \dot{V}_{\mathrm{E}}$ and $\mathrm{HR}$ and a significant decrease in RER, no change in spatiotemporal gait parameters of SL and cadence. When investigating performance determinants, the results indicated that $F$ and $\mathrm{Cr}$ explained $61 \%$ of the variance in performance time, whilst $\dot{V} \mathrm{O}_{2 \max }$ did not contribute to or correlate with overall performance time. However, it must be noted that due to the homogeneity of the participants $\left(\dot{V} \mathrm{O}_{2 \max } 60.4 \pm 5.8 \mathrm{ml} \cdot \mathrm{kg}^{-1} \cdot \mathrm{min}^{-1}\right)$, $\dot{V} \mathrm{O}_{2 \max }$ may prove to contribute additionally to overall performance in a more heterogenous group.

To allow comparison to a real-life race scenario, participants freely selected their running speed throughout the ultramarathon, bar a 3 min period at the control speed of $8 \mathrm{~km} \cdot \mathrm{h}^{-1}$ every $16.1 \mathrm{~km}$ from the start. Elapsed mean 
Fig. 2 Change in spatiotemporal parameters a Cadence (SPM) b stride length $(\mathrm{m})$ measured at $16.1 \mathrm{~km}$ intervals at the control speed of $8 \mathrm{~km} \cdot \mathrm{h}^{-1}$ Data is presented as means $\pm \mathrm{SD}$
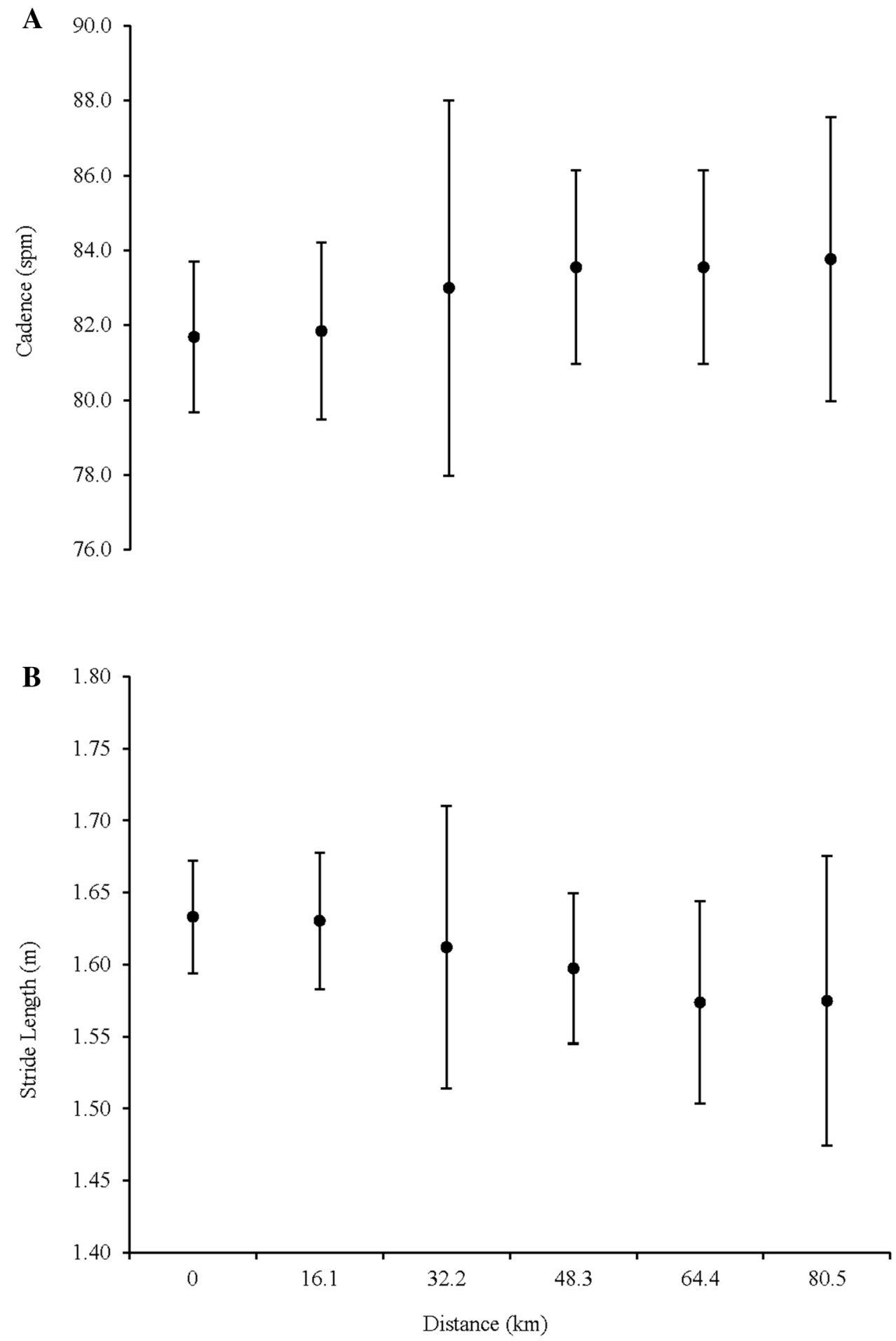

running speeds were between 7.6 and $11.4 \mathrm{~km} \cdot \mathrm{h}^{-1}$, with a mean speed decrease of $2.2 \pm 0.9 \mathrm{~km} \cdot \mathrm{h}^{-1}$ observed between the first and second half of the $80.5 \mathrm{~km}$ distance, the variation of which illustrates the requirement to use a consistent controlled speed for analysis.

To date, evidence relating to oxygen cost and $\mathrm{Cr}$ in ultramarathons has been conflicting (Balducci et al. 2017;
Fusi et al. 2008; Gimenez et al. 2013; Schena et al. 2014; Vernillo et al. 2014,2015,2016), owing mainly to the variance in event distance/duration as well as terrain and environmental conditions. Therefore, using a laboratory-based study design enabled the standardisation and control of conditions. Here, we observed an increase in both the $\dot{V} \mathrm{O}_{2}$ and Cr (Fig. 1a, b) at the control speed. Whilst the increase in $\dot{V}$ 
Fig. 3 Relationship between the mean fractional utilistation of $\dot{V}$ $\mathrm{O}_{2 \max }$ as a percentage of $\dot{V} \mathrm{O}_{2 \max }$ $(F)$ (closed circles and black dashed line) and the percentage of $\dot{V} \mathrm{O}_{2 \max }$ (open circles and grey dashed line) sustained during the $80.5 \mathrm{~km}$ trial compared to change in energy cost of running at the control speed from start to finish of the $80.5 \mathrm{~km}$ trial $\Delta \mathrm{Cr}(\%)$
Fig. 4 Relationship between the percentage change in SL $[\Delta \mathrm{SL}$ (\%)] (closed circles and black dashed line) and the percentage change in running cadence [ $\Delta$ cadence $(\%)]$ (open circles and grey dashed line) during the $80.5 \mathrm{~km}$ trial compared to change in energy cost of running at the control speed from start to finish of the $80.5 \mathrm{~km}$ trial $\Delta \mathrm{Cr}(\%)$
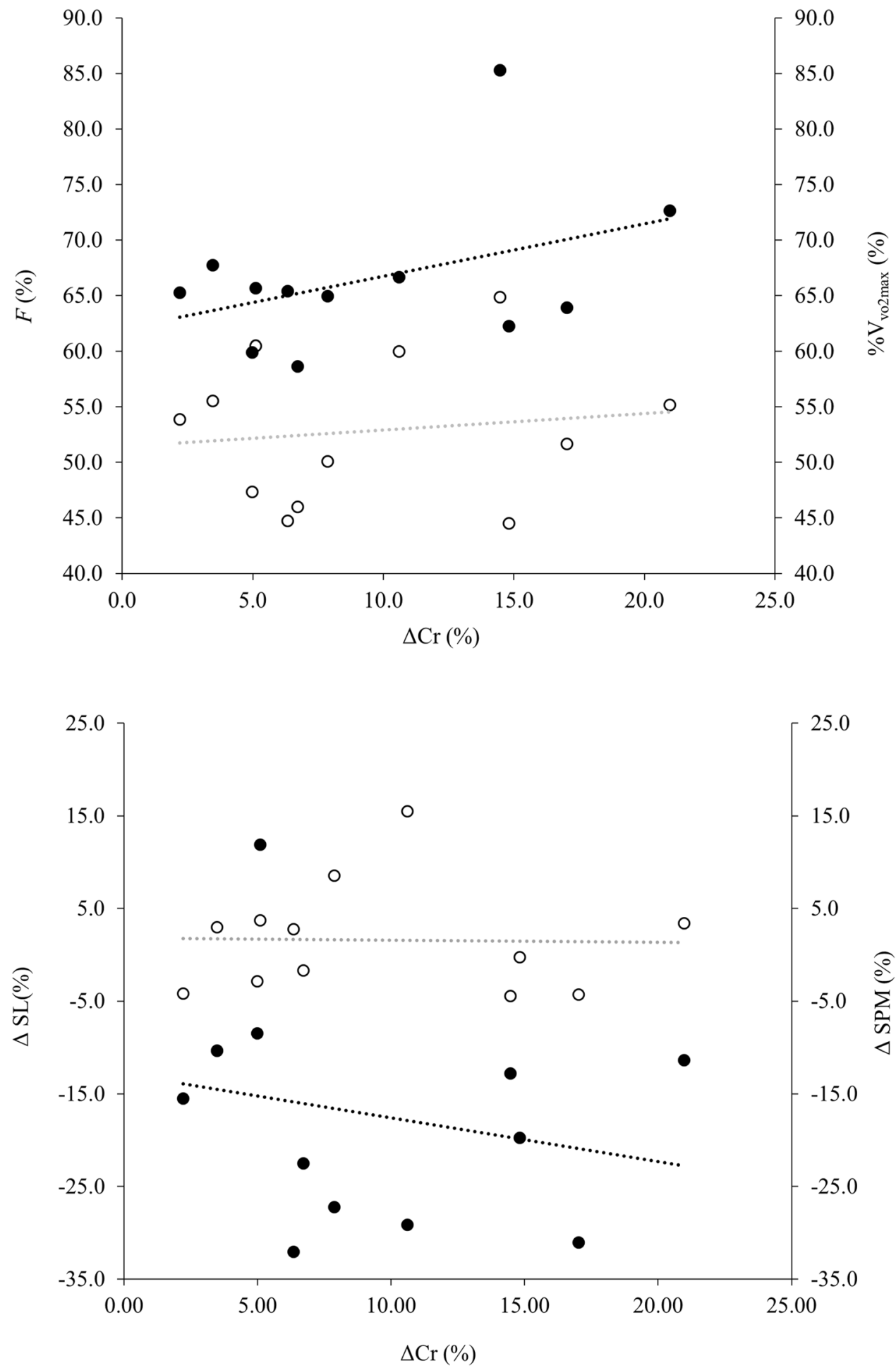

$\mathrm{O}_{2}$ and $\mathrm{Cr}$, both follow similar upward trends throughout the $80.5 \mathrm{~km}$ trial, the significant decrease in RER from the start of the trial to the $32 \mathrm{~km}$ measurement distance marginally reduces the increase in $\mathrm{Cr}$ compared to $\mathrm{VO}_{2}$ alone, through the inclusion of substrate utilisation (RER). The shift to fatty acid oxidation is well documented in the literature (Brueckner et al. 1991; Costill 1970; Howe et al. 2018), and this corresponds with the related increase in $\mathrm{Cr}$ occurring in the first $32 \mathrm{~km}$ [02:45:03 \pm 00:25:58 (hrs:mins:sec)] before the observed plateau (Fig. 1e). The shift to fatty acid oxidation has also been confirmed using a novel untargeted metabolomic approach in the same cohort, which was demonstrated by a marked increase in peroxisomal metabolism providing acetyl carnitines for export to mitochondria in the muscles 
(Howe et al. 2018). Whilst the findings in this study are in agreement with previous literature (Gimenez et al. 2013; Lazzer et al. 2012), the plateau in RER occurred much earlier at $\sim 3 \mathrm{~h}$ compared to a significant decrease in RER up to the $8 \mathrm{~h}$ time point before plateauing during a $24 \mathrm{~h}$ treadmill ultramarathon at the same control speed of $8 \mathrm{~km} \cdot \mathrm{h}^{-1}$ (Gimenez et al. 2013). The difference observed here may partly be explained by the shorter distance $(80.5 \mathrm{~km}$ vs. mean $149.2 \pm 15.7 \mathrm{~km})$ and higher $F$ sustained by the participants in this study ( $52.8 \pm 6.7 \%$ vs. $39 \pm 4 \%)$, due to an accelerated glycogen depletion and therefore a more rapid shift to fatty acid oxidation with a $F$. In addition, participants were asked to cover the $80.5 \mathrm{~km}$ in the 'fastest possible time' whereas in the study of Gimenez et al. (2013), participants were instructed to achieve the 'greatest distance' in a given time period ( $24 \mathrm{~h}$ ), suggesting individual pacing and perception of effort required may be a factor in the difference in RER plateaus. The lower trained status of the ultramarathon runners in the study conducted by Gimenez and colleagues (2013) compared to this study $\left(\dot{V} \mathrm{O}_{2 \max } 52.0 \pm 6.3\right.$ vs. $60.4 \pm 5.8 \mathrm{ml} \cdot \mathrm{kg}^{-1} \cdot \mathrm{min}^{-1}$, respectively) may also explain the difference, with more trained individuals having a greater ability to oxidise fat (Purdom et al. 2018). When looking at self-selected running speed, there is no change in $\dot{V} \mathrm{O}_{2}$, with a significant decrease in $F$ and significant increase in $\mathrm{Cr}$ over the course of the $80.5 \mathrm{~km}$ ultramarathon. Both the $\dot{V} \mathrm{O}_{2}$ and $F$ data can be explained by the decrease in running speed through the trial, whilst the increase in $\mathrm{Cr}$ despite the decrease in running speed is part explained by the significant decrease in RER mirroring that observed at the control speed. However, it must be recognised as a potential limitation that the variance in individual self-selected running speeds chosen by the participants could influence the data collected at the control speed, especially as control speed was much lower for some participants compared to selfselected running speeds, but less so later in the trial when self-selected and control speeds were similar. To mitigate for this, sufficient time allowed 'steady-state' to be reached at the control speed when measuring metabolic variables $(\dot{V}$ $\mathrm{O}_{2}, \dot{V} \mathrm{CO}_{2}$ and $\dot{V}_{\mathrm{E}}$ ).

The increase in $\mathrm{Cr}$ during ultra-endurance exercise is still not fully understood (Gimenez et al. 2013), although several suggestions have been proposed. For example, an increase in $\dot{V}_{\mathrm{E}}$ and its association with higher respiratory frequency has been suggested in shorter duration events (Davies and Thompson 1986; Millet et al. 2000), which is supported in our findings, such that a significant increase in $\dot{V}_{\mathrm{E}}$ was evident between the start and end of the $80.5 \mathrm{~km}$ ultramarathon (Fig. 1d). Interestingly, this was not observed in a $24 \mathrm{~h}$ treadmill run where $\dot{V}_{\mathrm{E}}$ did not significantly change over the course of the exercise (Gimenez et al. 2013), perhaps due to the difference in mean running speed between the studies $7.9 \pm 1.0 \mathrm{~km} \cdot \mathrm{h}^{-1}$ for the $24 \mathrm{~h}$ treadmill vs. $10.3 \pm 1.3 \mathrm{~km} \cdot \mathrm{h}^{-1}$.
Caillaud and colleagues (1995), proposed the increase in $\mathrm{Cr}$ is due to the increase in $\dot{V}_{\mathrm{E}}$ attributed to the change in $\mathrm{O}_{2}$ diffusion across the alveolar-capillary membrane, however, this was not measured in the current study and therefore warrants further investigation in prolonged ultra-endurance activities. Further explanations for an increase in $\mathrm{Cr}$ may be peripheral muscular alterations (Gimenez et al. 2013), a reduction in mitochondrial efficiency (Fernström et al. 2007), and changes in muscle activation, efficiency, or in biomechanical parameters, such as stride frequency (Morin et al. 2011a). However, although there was a slight upward trend in cadence and slight downward trend in SL, no statistically significant changes were observed in these spatiotemporal parameters at the control speed (Fig. 2). This is likely to be the result of changing the speed resulting in a forced alteration of running gait. This adaptation in control speed may have required in some instance a reduction/change in preferred SL and frequency. While sufficient time allowed 'steady state' to be reached at the control speed for metabolic variables, it may not have been long enough for the stabilisation of gait patterns. This may therefore have resulted in a wider range of speed alterations for some, resulting in greater gait variability. Future investigations should consider the inclusion of ground contact time and duty cycle data to estimate force generation capacity of the leg and increases in metabolic energy expenditure to further explore the mechanisms involved in the increase in $\mathrm{Cr}$ (Beck et al. 2020; Taylor and Kram 1990).

It has previously been demonstrated that an increase in SPM coupled with a decrease in SL occurs over the duration of an ultramarathon to adopt a "smoother" or "safer" running technique (Vernillo et al. 2019). This was not observed in the currently study, potentially due to the differences between over-ground and treadmill running and no natural variation in terrain, and the reduced braking and propulsive forces experienced and more ordered control in gait whilst running on a treadmill (Lindsay et al. 2014). However, changes are potentially explained by the fatiguing nature of an ultramarathon, with increased muscle damage and inflammation along with reduction in muscle force generation over the gait cycle, resulting in a safer running technique being adopted to limit further damage, leading to a greater $\mathrm{Cr}$ due to the newly adopted cadence and stride length (Morin et al. 2011; Vernillo et al. 2019). Furthermore, it has been demonstrated that participants who maintained the highest $\% \mathrm{~V}_{\dot{V O}_{2 \text { max }}}$ during a $24 \mathrm{~h}$ treadmill ultramarathon also displayed the largest deterioration in $\mathrm{Cr}$, which raises the question that a lower $\mathrm{Cr}$ is of less significance in ultramarathon performance (Gimenez et al. 2013). However, there was no correlation observed between those participants that maintained the highest $F(\%)$ and $\% \mathrm{~V}_{\dot{V} \mathrm{O}_{2 \max }}$ with the largest increases in $\mathrm{Cr}$ (Fig. 3), nor between those who had the great change in $\mathrm{SL}$ and cadence and $\Delta \mathrm{Cr}$ (Fig. 4). This therefore indicates 
that $\dot{V} \mathrm{O}_{2 \max }$ did not contribute to overall performance, with $F$ and $\mathrm{Cr}$ explaining $61 \%$ of variance in finish time. It has previously been reported that as distance increases, $\dot{V} \mathrm{O}_{2 \max }$ becomes of less importance (Davies and Thompson 1979; Sjödin and Svedenhag 1985), however, having a high $\dot{V} \mathrm{O}_{2 \max }$ enables a higher submaximal speed or $F$ to be maintained (Millet et al. 2011), which may indicate why $F$ demonstrated great predictive power of performance in the current study. The current findings contradict those of Lazzer et al. (2012) where $87 \%$ of performance time was attributed to $\dot{V} \mathrm{O}_{2 \max }, F$ and $\mathrm{Cr}$ in a 3 days ultra-endurance running event, however, in their study, HR was used as a estimation of $F$, which may lead to small but systematic errors, compared to indirect calorimetry that was used in the current study. To the authors' knowledge, the current study is one of very few studies to directly measure these variables during an ultramarathon.

While no changes were observed at the control speed, there was a significant reduction in SL at self-selected speeds over the course of the ultramarathon, which is a function of a reduction in running speed but again this indicates suggests that runners naturally selected a cadence and SL that is optimal or very near to being economically optimal (Moore et al. 2012; Moore 2016; Williams and Cavanagh 1987). Indeed, this difference was likely a result of the controlled speed producing forced alterations in running gait. There was no change in running cadence during selfselected running speeds, and a potential explanation for the increase in $\mathrm{Cr}$ with no significant change in spatiotemporal parameters, maybe the change in mechanical properties of the Achilles tendon, such as demonstrated following a 90 min submaximal run which showed a small but significant increase in $\mathrm{Cr}$, by increased muscle fascicle shortening (Fletcher and MacIntosh 2018). Though, it must be noted, that the alternations in running speed between self-selected and control, may have also contributed to this. As mechanical properties were not measured, it should be taken into consideration when designing future investigation into the mechanisms behind changes in $\mathrm{Cr}$ in ultramarathon distance events. It is important to acknowledge the benefits and constraints of using a treadmill to analysis running performance. In a recent systematic review and meta-analysis, there was no difference observed between over-ground running and motorised treadmill running for submaximal $\dot{V} \mathrm{O}_{2}$, heart rate and perceived effort; however, preferred submaximal running speeds were slower and blood lactate concentrations were lower whilst running on a treadmill compared to over-ground (Miller et al. 2019). Whilst, significant differences in ground reaction forces and kinematic variables were observed between over-ground and graded treadmill running, the differences were small and the researchers believe that variables measured on a treadmill may be applicable to over-ground running (Firminger et al. 2018). This is further supported by a meta-analysis comparing biomechanical measures between over-ground and treadmill running, where spatiotemporal, kinematic, kinetic, muscle activity, and muscle-tendon measures were widely comparable (Van Hooren et al. 2019). Therefore, the authors feel confident that the data presented have ecological validity to external ultramarathon events with minimal course elevation.

\section{Conclusion}

It has previously been demonstrated that that a greater $\dot{V}$ $\mathrm{O}_{2 \max }$, higher $F$ and lower $\mathrm{Cr}$ all contribute to successful endurance performance (Gimenez et al. 2013; Joyner and Coyle 2008; Lazzer et al. 2012; Millet et al. 2011; Saunders et al. 2004). However, in this treadmill ultramarathon, $\dot{V} \mathrm{O}_{2 \max }$ did not contribute to overall performance, with $F$ and $\mathrm{Cr}$ explaining $61 \%$ of variance in finish time. In this participant cohort, $\dot{V} \mathrm{O}_{2 \max }$ is less of a performance predictor than $F$ and $\mathrm{Cr}$ as event distance increases. Those able to maintain a higher $F$ while adopting strategies to minimise an increase in $\mathrm{Cr}$ may be best placed to maximise ultramarathon performance from a physiological standpoint. The small sample size, homogeneity and relatively high training status of the cohort along with a large number of other potential performance determinates (lab versus field study, nutritional and psychological factors) that may contribute to overall ultramarathon performance (Howe et al. 2019), mean that further research needs to be carefully designed (Vernillo et al. 2017) to adequately measure and establish as many key performance determinants as possible. This would then enable a better understanding of the limiting factors of extreme human performance.

Acknowledgements The authors would like to thank the participants for their time and effort in completing the study.

Author's contributions CCFH, OS, EKLP, and HJM conceived and designed the study. CCFH, AK and HJM conducted the experiments. $\mathrm{CCFH}$ and NS analysed the data. All authors interpreted the results of study. CCFH drafted the manuscript and prepared figures/tables. All authors edited and revised the manuscript. All authors approved the final version of the manuscript.

Funding The authors received no financial support for the research, authorship, and/or publication of this article.

Data availability The datasets generated during and/or analysed during the current study are available from the corresponding author on reasonable request.

\section{Compliance with ethical standards}

Conflict of interest The authors declare that they have no conflicts of interest to report. 
Ethics approval The authors declare that the results of the study are presented clearly, honestly, and without fabrication, falsification, or inappropriate data manipulation in any way to intentionally portray anything but those outcomes that were observed. The Faculty of Science, Engineering and Computing Ethics Committee at Kingston University London approved the study in accordance with the Declaration of Helsinki.

Consent to participate (include appropriate statements) Written informed consent was obtained from all individual participants included in the study.

Consent for publication (include appropriate statements) Participants provided informed consent for the publication of their anonymised data.

Open Access This article is licensed under a Creative Commons Attribution 4.0 International License, which permits use, sharing, adaptation, distribution and reproduction in any medium or format, as long as you give appropriate credit to the original author(s) and the source, provide a link to the Creative Commons licence, and indicate if changes were made. The images or other third party material in this article are included in the article's Creative Commons licence, unless indicated otherwise in a credit line to the material. If material is not included in the article's Creative Commons licence and your intended use is not permitted by statutory regulation or exceeds the permitted use, you will need to obtain permission directly from the copyright holder. To view a copy of this licence, visit http://creativecommons.org/licenses/by/4.0/.

\section{References}

Balducci P, Clémençon M, Trama R, Blache Y, Hautier C (2017) Performance factors in a mountain ultramarathon. Int J Sports Med 38:819-826. https://doi.org/10.1055/s-0043-112342

Beck ON, Kipp S, Byrnes WC, Kram R (2018) Use aerobic energy expenditure instead of oxygen uptake to quantify exercise intensity and predict endurance performance. J Appl Physiol 125:672-674. https://doi.org/10.1152/japplphysiol.00940.2017

Beck ON, Gosyne J, Franz JR, Sawicki GS (2020) Cyclically producing the same average muscle-tendon force with a smaller duty increases metabolic rate. Proc Royal Soc Bio Sci. 287:20200431. https://doi.org/10.1098/rspb.2020.0431

Bigland-Ritchie B, Woods JJ (1974) Integrated EMG and oxygen uptake during dynamic contractions of human muscles. J Appl Physiol 36:475-479. https://doi.org/10.1152/jappl.1974.36.4.475

Brueckner JC, Atchou G, Capelli C et al (1991) The energy cost of running increases with the distance covered. Eur J Appl Physiol 62:385-389. https://doi.org/10.1007/bf00626607

Burns GT, Zendler JM (1985) Zernicke RF (2019) Step frequency patterns of elite ultramarathon runners during a $100-\mathrm{km}$ road race. J Appl Phys 126:462-468. https://doi.org/10.1152/japplphysi ol.00374.2018

Caillaud C, Serre-Cousine O, Anselme F, Capdevilla X, Prefaut C (1995) Computerized tomography and pulmonary diffusing capacity in highly trained athletes after performing a triathlon. J Appl Phys 79:1226-1232. https://doi.org/10.1152/jappl.1995.79.4.1226

Cavanagh PR, Kram R (1989) Stride length in distance running: velocity, body dimensions, and added mass effects. Med Sci Sports Exerc 21:467-479. https://doi.org/10.1249/00005768-19890 $8000-00020$
Cavanagh PR, Williams KR (1982) The effect of stride length variation on oxygen uptake during distance running. Med Sci Sports Exerc 14:30-35. https://doi.org/10.1249/00005768-198201000-00006

Conley DL, Krahenbuhl GS (1980) Running economy and distance running performance of highly trained athletes. Med Sci Sports Exerc 12:357-360. https://doi.org/10.1249/00005768-19802 $5000-00010$

Costill DL (1970) Metabolic responses during distance running. J Appl Physiol 28:251-255. https://doi.org/10.1152/jappl.1970.28.3.251

Daniels JT (1985) A physiologist's view of running economy. Med Sci Sports Exerc 17:332-338. https://doi.org/10.1249/00005768198506000-00006

Davies CT, Thompson MW (1979) Aerobic performance of female marathon and male ultramarathon athletes. Eur J Appl Physiol 41:233-245. https://doi.org/10.1007/BF00429740

Davies CT, Thompson MW (1986) Physiological responses to prolonged exercise in ultramarathon athletes. J Appl Physiol (1985) 61:611-617. https://doi.org/10.1152/jappl.1986.61.2.611

de Ruiter CJ, Verdijk PWL, Werker W, Zuidema MJ, de Haan A (2014) Stride frequency in relation to oxygen consumption in experienced and novice runners. Eur J Sport Sci 14:251-258. https:// doi.org/10.1080/17461391.2013.783627

Degache F, Morin J, Oehen L et al (2016) Running mechanics during the World's most challenging mountain Ultramarathon. Int J Sports Physiol Perform 11:608-614. https://doi.org/10.1123/ijspp .2015-0238

DUV Ultra Marathon Statistics [Internet]. [cited 2019 Oct 09]. Available from: http://statistik.d-u-v.org No title.

Fernström M, Bakkman L, Tonkonogi M et al (2007) Reduced efficiency, but increased fat oxidation, in mitochondria from human skeletal muscle after $24 \mathrm{~h}$ ultraendurance exercise. Physiol Adv Racing 102:1844. https://doi.org/10.1152/japplphysiol.01173 .2006

Field A (2018) Discovering statistics using IBM SPSS Statistics, 5 edn. The Bookwatch

Firminger CR, Vernillo G, Savoldelli A, Stefanyshyn DJ, Millet GY, Edwards WB (2018) Joint kinematics and ground reaction forces in overground versus treadmill graded running. Gait Posture 63:109-113. https://doi.org/10.1016/j.gaitpost.2018.04.042

Fletcher JR, MacIntosh BR (2018) Changes in Achilles tendon stiffness and energy cost following a prolonged run in trained distance runners. PLoS ONE 13:e0202026. https://doi.org/10.1371/journ al.pone. 0202026

Fletcher JR, Esau SP, MacIntosh BR (2009) Economy of running: beyond the measurement of oxygen uptake. J Appl Physiol 107:1918-1922. https://doi.org/10.1152/japplphysiol.00307.2009

Foster C, Lucia A (2007) Running economy. Sports Med 37:316-319. https://doi.org/10.2165/00007256-200737040-00011

Fusi S, Salvadego D, Bresadola V (2008) Maximal oxygen consumption and energy cost of running after a long-lasting running race: the $100 \mathrm{~km}$ of Sahara. Sport Sci Health 2:93-100. https://doi. org/10.1007/s11332-008-0046-6

Gimenez P, Kerherve H, Messonnier LA, Feasson L, Millet GY (2013) Changes in the energy cost of running during a $24 \mathrm{~h}$ treadmill exercise. Med Sci Sports Exerc 45:1807-1813. https://doi. org/10.1249/MSS.0b013e318292c0ec

Hoffman MD, Ong JC, Wang G (2010) Historical analysis of participation in $161 \mathrm{~km}$ Ultramarathons in North America. Int J Hist Sport 27:1877-1891. https://doi.org/10.1080/09523367.2010.494385

Howe C, Alshehri A, Muggeridge D et al (2018) Untargeted metabolomics profiling of an $80.5 \mathrm{~km}$ simulated treadmill Ultramarathon. Metabolites 8:14. https://doi.org/10.3390/metabo8010014 
Howe C, Pummell E, Pang S, Spendiff O, Moir HJ (2019) Trait emotional intelligence, mood states and cortisol response to a treadmill ultramarathon. J Sci Med Sport 22:763-768. https://doi. org/10.1016/j.jsams.2019.02.008

Ingham SA, Whyte GP, Pedlar C, Bailey DM, Dunman N, Nevill AM (2008) Determinants of $800 \mathrm{~m}$ and $1500 \mathrm{~m}$ running performance using allometric models. Med Sci Sports Exerc 40:345. https:// doi.org/10.1249/mss.0b013e31815a83dc

Jones AM, Doust JH (1996) A 1\% treadmill grade most accurately reflects the energetic cost of outdoor running. J Sports Sci 14:321327. https://doi.org/10.1080/02640419608727717

Joyner MJ, Coyle EF (2008) Endurance exercise performance: the physiology of champions. J Physiol 586:35-44. https://doi. org/10.1113/jphysiol.2007.143834

Knechtle B (2012) Ultramarathon runners: nature or nurture? Int J Sports Physiol Perform 7:310-312. https://doi.org/10.1123/ijspp 7.4.310

Knechtle B, Nikolaidis PT (2018) Physiology and pathophysiology in ultra-marathon running. Front Physiol 9:634. https://doi. org/10.3389/fphys.2018.00634

Krouse RZ, Ransdell LB, Lucas SM, Pritchard ME (2011) Motivation, goal orientation, coaching, and training habits of women ultrarunners. J Strength Cond Res 25(10):2835-2842. https://doi. org/10.1519/JSC.0b013e318204caa0

Lazzer S, Salvadego D, Rejc E et al (2012) The energetics of ultraendurance running. Eur J Appl Physiol 112:1709-1715. https:// doi.org/10.1007/s00421-011-2120-z

Lazzer S, Taboga P, Salvadego D et al (2014) Factors affecting metabolic cost of transport during a multi-stage running race. J Exp Bio 217:787-795. https://doi.org/10.1242/jeb.091645

Lazzer S, Salvadego D, Taboga P, Rejc E, Giovanelli N, di Prampero PE (2015) Effects of the etna uphill ultramarathon on energy cost and mechanics of running. Int J Sports Physiol Perform 10:238247. https://doi.org/10.1123/ijspp.2014-0057

Lee JB, Mellifont RB, Burkett BJ (2010) The use of a single inertial sensor to identify stride, step, and stance durations of running gait. J Sci Med Sport 13:270-273. https://doi.org/10.1016/j.jsams .2009.01.005

Lindsay TR, Noakes TD, McGregor SJ (2014) Effect of treadmill versus overground running on the structure of variability of stride timing. Percept Mot Skills 118:331-346. https://doi. org/10.2466/30.26.pms.118k18w8

Miller JR, Van Hooren B, Bishop C, Buckley JD, Willy RW, Fuller JT (2019) A systematic review and meta-analysis of crossover studies comparing physiological, perceptual and performance measures between treadmill and overground running. Sports Med 49:763782. https://doi.org/10.1007/s40279-019-01087-9

Millet G, Lepers R, Lattier G, Martin V, Babault N, Maffiuletti N (2000) Influence of ultra-long-term fatigue on the oxygen cost of two types of locomotion. Eur J Appl Physiol 83:376-380. https:// doi.org/10.1007/s004210000313

Millet G, Lepers R, Maffiuletti N, Babault N, Martin V, Lattier G (2002) Alterations of neuromuscular function after an ultramarathon. J Appl Physiol 92:486-492. https://doi.org/10.1152/jappl physiol.00122.2001

Millet GY, Banfi JC, Kerherve H et al (2011) Physiological and biological factors associated with a $24 \mathrm{~h}$ treadmill ultra-marathon performance. Scand J Med Sci Sports 21:54-61. https://doi.org/1 0.1111/j.1600-0838.2009.01001.x

Moore IS (2016) Is There an economical running technique? A review of modifiable biomechanical factors affecting running economy. Sports Med 46:793-807. https://doi.org/10.1007/s4027 9-016-0474-4
Moore IS, Jones AM, Dixon SJ (2012) Mechanisms for improved running economy in beginner runners. Med Sci Sports Exerc 44:1756-1763. https://doi.org/10.1249/mss.0b013e318255a727

Morin J, Sève P (2011) Sprint running performance: comparison between treadmill and field conditions. Eur J Appl Physiol 111:1695-1703. https://doi.org/10.1007/s00421-010-1804-0

Morin JB, Tomazin K, Edouard P, Millet GY (2011a) Changes in running mechanics and spring-mass behavior induced by a mountain ultra-marathon race. J Biomech 44:1104-1107. https://doi. org/10.1016/j.jbiomech.2011.01.028

Morin J, Samozino P, Millet GY (2011b) Changes in running kinematics, kinetics, and spring-mass behavior over a $24 \mathrm{~h}$ Run. Med Sci Sports Exerc 43:829-836. https://doi.org/10.1249/mss.0b013 e3181fec518

Nieman DC, Dumke CL, Henson DA, McAnulty SR, Gross SJ, Lind RH (2005) Muscle damage is linked to cytokine changes following a $160 \mathrm{~km}$ race. Brain Behav Immun 19:398-403. https://doi. org/10.1016/j.bbi.2005.03.008

Péronnet F, Massicotte D (1991) Table of nonprotein respiratory quotient: an update. Can J Sport Sci 16:23-29

Purdom T, Kravitz L, Dokladny K, Mermier C (2018) Understanding the factors that effect maximal fat oxidation. J Int Soc Sports Nutr 15:3. https://doi.org/10.1186/s12970-018-0207-1

Rüst C, Rosemann T, Knechtle B (2014) Performance and sex difference in ultra-triathlon performance from Ironman to double Deca Iron ultra-triathlon between 1978 and 2013. Springerplus 3:1-17. https://doi.org/10.1186/2193-1801-3-219

Saunders PU, Pyne DB, Telford RD, Hawley JA (2004) Factors affecting running economy in trained distance runners. Sports Med 34:465-485. https://doi.org/10.2165/00007256-200434070-00005

Scheer V, Vieluf S, Cramer L, Jakobsmeyer R, Heitkamp H (2018) Changes in running economy during a $65 \mathrm{~km}$ Ultramarathon. Front Physiol 9:1809. https://doi.org/10.3389/fphys.2018.01809

Schena F, Pellegrini B, Tarperi C, Calabria E, Luca Salvagno G, Capelli C (2014) Running economy during a simulated $60 \mathrm{~km}$ trial. Int J Sports Physiol Perform 9:604-609. https://doi.org/10.1123/ijspp .2013-0302

Sjödin B, Svedenhag J (1985) Applied physiology of marathon running. Sports Med (Auckland) 2:83-99. https://doi.org/10.2165/00007 256-198502020-00002

Stainsby WN, Barclay JK (1970) Exercise metabolism: $\mathrm{O}_{2}$ deficit, steady level $\mathrm{O}_{2}$ uptake and $\mathrm{O}_{2}$ uptake for recovery. Med Sci Sports 2:177-181

Taylor CR, Kram R (1990) Energetics of running: a new perspective. Nature (London) 346:265-267. https://doi.org/10.1038/346265a0

Van Hooren B, Fuller JT, Buckley JD et al (2019) Is motorized treadmill running biomechanically comparable to overground running? A systematic review and meta-analysis of cross-over studies. Sports Med (Auckland) 50:785-813. https://doi.org/10.1007/ s40279-019-01237-z

Vernillo G, Savoldelli A, Zignoli A et al (2014) Influence of the world's most challenging mountain ultra-marathon on energy cost and running mechanics. Eur J Appl Physiol 114:929-939. https://doi. org/10.1007/s00421-014-2824-y

Vernillo G, Savoldelli A, Zignoli A et al (2015) Energy cost and kinematics of level, uphill and downhill running: fatigue-induced changes after a mountain ultramarathon. J Sports Sci 33:19982005. https://doi.org/10.1080/02640414.2015.1022870

Vernillo G, Savoldelli A, Skafidas S et al (2016) An extreme mountain ultra-marathon decreases the cost of uphill walking and running. Front Physiol 7:530. https://doi.org/10.3389/fphys.2016.00530 
Vernillo G, Millet GP, Millet GY (2017) Does the running economy really increase after ultra-marathons? Front Physiol 8:783. https ://doi.org/10.3389/fphys.2017.00783

Vernillo G, Doucende G, Cassirame J, Mourot L (2019) Energetically optimal stride frequency is maintained with fatigue in trained ultramarathon runners. J Sci Med Sport 22:1054-1058. https:// doi.org/10.1016/j.jsams.2019.04.003

Williams KR, Cavanagh PR (1987) Relationship between distance running mechanics, running economy, and performance. J Appl
Physiol (1985) 63:1236-1245. https://doi.org/10.1152/jappl 1987.63.3.1236

Wuthrich TU, Marty J, Kerherve H, Millet GY, Verges S, Spengler CM (2015) Aspects of respiratory muscle fatigue in a mountain ultramarathon race. Med Sci Sports Exerc 47:519-527. https:// doi.org/10.1249/MSS.0000000000000449

Publisher's Note Springer Nature remains neutral with regard to jurisdictional claims in published maps and institutional affiliations. 